\title{
The effect of plant development on thrips resistance in Capsicum
}

\author{
Pauline van Haperen ${ }^{1,2} \cdot$ Roeland E. Voorrips ${ }^{1} \cdot$ Joop J. A. van Loon ${ }^{2} \cdot$ Ben Vosman $^{1}$
}

Received: 28 March 2018 / Accepted: 25 September 2018 / Published online: 8 October 2018

(c) The Author(s) 2018

\begin{abstract}
Western flower thrips [Frankliniella occidentalis (Pergande)] is a worldwide pest insect that causes damage in pepper cultivation, so growers would benefit from host plant resistance. The objectives of this study were (1) to evaluate the effect of plant age on thrips resistance using nine Capsicum accessions with different levels of thrips resistance at three different plant ages, and (2) to study the effect of leaf age on thrips resistance in a resistant and a susceptible pepper accession. The fraction of first instar larvae that did not develop into second instar was used as a measure for thrips resistance. Our results show that plants start to develop thrips resistance when they are between 4 and 8 weeks old. This transition was most marked on the resistant accession CGN16975, on which about 50\% of the L1 larvae developed into the next stage on 4-week-old plants, whereas none of them developed beyond the L1 stage on 8- or 12-week-old plants. Furthermore, it is shown that youngest fully opened leaves of the resistant accession CGN16975 are significantly more resistant to thrips than older leaves; 89\% of the L1 larvae did not develop into the next stage on the youngest leaves, whereas 57\% did not develop beyond the L1 stage on the oldest leaves. Young leaves of the susceptible accession CGN17219 are more susceptible than older leaves; 9 versus $52 \%$ of the L1 larvae did not develop into the next stage on young and old leaves, respectively. These findings can be used to improve integrated pest management strategies.
\end{abstract}

Keywords Host plant resistance $\cdot$ Plant age $\cdot$ Leaf age $\cdot$ Frankliniella occidentalis

\section{Introduction}

Thrips is a worldwide pest insect in agricultural and horticultural crops (Kirk and Terry 2003). The most important thrips species in Capsicum in Europe is western flower thrips [Frankliniella occidentalis (Pergande)], causing constraints to pepper production both in the field and in the greenhouse (Siemonsma and Kasem 1994; Tommasini and Maini 1995). Thrips can damage plants both directly and indirectly. Direct

Handling Editor: Joe Louis.

Electronic supplementary material The online version of this article (https://doi.org/10.1007/s11829-018-9645-6) contains supplementary material, which is available to authorized users.

Ben Vosman

ben.vosman@wur.nl

1 Plant Breeding, Wageningen University and Research, P.O. Box 386, 6700 AJ Wageningen, The Netherlands

2 Laboratory of Entomology, Wageningen University and Research Centre, P.O. Box 16, 6700 AA Wageningen, The Netherlands damage is caused by feeding on the leaves, flowers and fruits, resulting in their deformation, reduced plant growth, altered carbon allocation and thus reduced yield (Welter et al. 1990; Shipp et al. 1998). Very characteristic is the "silvering damage" which is caused by thrips piercing the plant cells with their stylet-shaped mouth and sucking out the cell content, leaving silver leaf scars (Chisholm and Lewis 1984). Indirect damage is caused by the viruses they transmit, of which tomato spotted wilt virus (TSWV) is the most important one in pepper (German et al. 1992).

It is difficult to control thrips because of their high reproductive rate, short life cycle and cryptic behaviour (Cloyd 2009). Monitoring the thrips population and limiting its growth to prevent an outbreak is therefore important. This can at least partly be accomplished by using cultural, mechanical, physical and biological control (Mouden et al. 2017). In addition to these protective measures, it is highly desirable to identify plants that have a natural source of resistance against thrips, either constitutive or induced. Host plant resistance can be found in several plant species and in several forms (Smith 2005; Broekgaarden et al. 2011), for example, by the presence of a modified epicuticular wax 
layer on leaves of cabbage (Voorrips et al. 2008; Znidarcic et al. 2008), or by the production of specific compounds such as acylsugars that have a negative effect on insects (Mirnezhad et al. 2010; Glas et al. 2012).

Host plant resistance to insects has been found in a large number of crops. In some cases, the resistance is only expressed at specific plant developmental stages. For instance, the epicuticular lipids that play a role in resistance against herbivorous insects can vary with plant part, plant age and environmental condition (Eigenbrode and Espelie 1995). Another example is the increasing resistance in a Brassica oleracea cultivar against cabbage whitefly when these plants grow older (Broekgaarden et al. 2012). Similar findings have been reported in resistance of Solanum lycopersicum against tomato leaf miner (Leite et al. 2001). In addition, it has been shown that resistance levels may vary in different parts of the plant (De Kogel et al. 1997; Leiss et al. 2009).

Host plant resistance in pepper against thrips may also be affected by plant development. Maharijaya et al. (2011) screened several pepper accessions when the plants were 12 weeks old. Larval development and mortality was determined on the youngest fully opened leaves only (Maharijaya et al. 2012). Therefore, it is not known whether the host resistance against thrips that was identified by Maharijaya et al. (2011) changes during plant development, and whether the resistance varies between plants of different ages and leaves of different ages.

The aims of this study are to determine whether or not the resistance in pepper against thrips changes during plant development, and whether or not the level of resistance varies between leaves of the pepper plant. Based on previous studies on the effect of plant development on insect resistance (De Kogel et al. 1997; Leite et al. 2001; Leiss et al. 2009; Broekgaarden et al. 2012), we hypothesised that the level of resistance to thrips in young leaves increases with plant age, and that thrips resistance decreases with leaf age.

\section{Materials and methods}

\section{Plant material and growing conditions}

To study whether plant age affects thrips resistance, we used the same nine Capsicum accessions as Maharijaya et al. (2012), which were classified as susceptible, intermediate resistant and fully resistant to thrips, based on the damage to the youngest fully opened leaves by female adults of $F$. occidentalis and development of first instar larvae (L1). Seeds were obtained from the Centre of Genetic Resources, the Netherlands. Three groups of four plants of each accession were sown with a 4-week interval in potting compost in a greenhouse of Unifarm, Wageningen University and
Research, Wageningen, the Netherlands. Plants were grown at $25{ }^{\circ} \mathrm{C}$, with a photoperiod of L16:D8, and $70 \% \mathrm{RH}$. No insecticides were applied. Thrips were controlled biologically using the predatory hemipteran Orius laevigatus (Fieber) (Entocare C.V., Wageningen, the Netherlands). Plants were watered three times per week, two times per week nutrients were added. The three youngest fully opened leaves of each plant were evaluated for thrips resistance 12 weeks after the first group of plants was sown, so at plant ages of 12,8 and 4 weeks, respectively. Plants were not yet flowering when the youngest fully opened leaves were collected.

To study whether different levels of thrips resistance are found in leaves of different ages, we selected one resistant (CGN16975) and one susceptible (CGN17219) accession. Five plants of each accession were sown and grown in the same conditions as the plants of the plant age experiment. At a plant age of 12 weeks we collected leaves of five age classes (1-5, corresponding to a leaf age of about $0,2,4,6$ and 8 weeks, respectively) for use in a detached leaf assay for thrips resistance (Additional material 1, Electronic Supplementary Material 1). Three leaves of each leaf age class were collected per plant. These leaves were the three youngest fully opened leaves of each plant at a plant age of 12, 10, 8, 6 and 4 weeks. Plants of CGN16975 and CGN17219 had 4 and 6 real leaves, respectively, at a plant age of 4 weeks. Plants of both accessions showed the same number of leaves at a plant age of 6 weeks or older. The plants did not flower until after the leaves were evaluated for thrips resistance at the plant age of 12 weeks.

Plants from accessions CGN16975 and CGN17219 were used to determine the thrips damage in a no-choice whole plant damage assay. Five plants of each accession were sown and grown in the same conditions as the plants of the plant age experiment. Four weeks after sowing, the plants were enclosed in thrips-proof sleeves to prevent thrips from escaping from the plant.

Three plants from accession CGN16975 were used to study oviposition by female thrips. From each plant the main stem was removed at a plant age of 20 weeks, and the largest side branch that emerged from the base of the main stem was enclosed in a thrips-proof sleeve to prevent thrips from escaping. Each side branch contained at least 40 old and 40 young leaves. The plants were flowering at the start of the oviposition experiment.

\section{Thrips rearing}

A population of Frankliniella occidentalis (acquired from Greenhouse Horticulture of Wageningen University and Research, Bleiswijk, the Netherlands) was reared on Phaseolus vulgaris beans in glass rearing pots covered with thrips-proof gauze in a growth cabinet at $25{ }^{\circ} \mathrm{C}, \mathrm{L} 16: \mathrm{D} 8$, $70 \%$ relative humidity. Female adults were allowed to lay 
eggs on snack cucumbers for $24 \mathrm{~h}$, after which the thrips were brushed off and the cucumbers were kept in the growth cabinet at $25^{\circ} \mathrm{C}$. After 4 days, new synchronised first instar larvae (L1) emerged (Mollema et al. 1993).

\section{Detached leaf assay}

Each detached leaf, selected as discussed in the Plant material section, was placed with the petiole in a droplet of $1.5 \%$ water agar in a Petri dish (BD Falcon, tight-fit lid $50 \times 9 \mathrm{~mm})$. Five synchronised L1 larvae were placed on each detached leaf. The Petri dish was firmly closed to prevent the larvae from escaping. The Petri dishes were incubated at $25{ }^{\circ} \mathrm{C}$ in a growth cabinet. The developmental stage of each thrips was determined at day 3,5 and 7 post infestation. The fraction of larvae that did not develop from the first into the second larval stage (from L1 to L2) was used as a measure for thrips resistance. Larval development was more consistent as a measure for thrips resistance than larval survival. In some replicates, survival was affected by the condensation of water causing droplets on the lids of the firmly closed Petri dishes after 5-7 days that caused some larvae to drown. Since under optimal conditions, first instar larvae develop into second instar larvae in 1-2 days (Lublinkhof and Foster 1977), larval development was not affected by the formation of water droplets, and was therefore selected as resistance criterion.

\section{Whole plant damage assay}

For the whole plant damage assay, female adults were carefully collected by using an aspirator and anesthetised with carbon dioxide $\left(\mathrm{CO}_{2}\right)$. When 7 weeks old, plants were infested each with 20 female adult thrips. To ensure high thrips pressure, the infestation was repeated 1 week later. The five most damaged leaves of each plant were scored for silvering damage, caused by thrips feeding, when the plants were 10 weeks old. The plants did not yet flower when they were scored. The damage scale is shown in Table 1.

\section{Oviposition}

For the oviposition assay, female adults were carefully collected by using an aspirator and anesthetised with $\mathrm{CO}_{2}$. Each selected side branch was infested with 75 adult females. After 3 days, the 40 oldest and 40 youngest leaves of each side branch were removed and each leaf was placed in a separate Petri dish as described above. All adult thrips were removed. The leaf area was determined by analysing pictures of the leaves in ImageJ $1.51 \mathrm{f}$ (Schneider et al. 2012). The Petri dishes were incubated at $25{ }^{\circ} \mathrm{C}$ in a growth cabinet. Emerged larvae were counted and removed on 6, 8 and 10 days after the initial infestation. As the average development time from egg to the first instar is 3-4 days at $25^{\circ} \mathrm{C}$, we assumed that all viable eggs were hatched within 10 days after infestation (McDonald et al. 1998; Zhang et al. 2007). The average leaf area of young leaves and the average leaf area of old leaves, respectively, were used to determine the number of larvae per $\mathrm{cm}^{2}$ of leaf area per leaf age category.

\section{Statistical analysis}

The fractions of larvae arrested at the L1 stage were transformed as $y=\arcsin (\sqrt{ } x)$. Analysis of variance (ANOVA) was carried out to test for significant differences in larval development between plants and leaves of different ages. For the plant and leaf age experiment, a two-way ANOVA was carried out to determine the effects of age, accession and the interaction between age and accession, respectively. When significant $F$ values $(P<0.05)$ were obtained, all mean values in the plant and leaf age experiment, respectively, were compared using Fisher's Protected
Table 1 Evaluation scale for a whole plant thrips damage assay

\begin{tabular}{lll}
\hline $\begin{array}{l}\text { Leaf damage } \\
\text { scale }\end{array}$ & Description & $\begin{array}{l}\text { \% of } \\
\text { silvering } \\
\text { damage }\end{array}$ \\
\hline 1 & No damage & 0 \\
2 & Tiny silvering spots & $<0.1$ \\
3 & Some small spots near the mid vein or edge of the leaf & $0.1-1$ \\
4 & Moderate number of spots near the mid vein or edge of the leaf, or some & $1-2$ \\
& $\quad$ small spots more regularly distributed over the entire leaf & \\
5 & Moderate number of spots, more regularly distributed over the entire leaf & $3-5$ \\
7 & Intermediate between 5 and 7 & $6-10$ \\
8 & Many silvering spots over the entire leaf & $11-20$ \\
9 & Intermediate between 7 and 9 & $21-40$ \\
\hline
\end{tabular}

The five most affected leaves of each plant were evaluated. The damage scale is adapted from Linders et al. (2010) 
least-significant-difference (LSD) test. For the whole plant damage assay, a Mann-Whitney $U$ test was used to determine whether the differences between damage score of the most affected leaves of the two tested accessions were significant. For the oviposition assay, a Wilcoxon matched-pairs signed-ranks test was used to determine whether the differences between emerged larvae on old and young leaves per $\mathrm{cm}^{2}$ of leaf area were significant. These statistical analyses were conducted using GenStat 18th edition (VSN International 2015).

\section{Results}

\section{Plant age experiment}

The two-way ANOVA showed a significant interaction between accession and plant age in their effect on the fraction of larvae arrested at the first instar stage $(P<0.001$, Table 2$)$. A significant effect of plant age on larval development was

Table 2 Two-way ANOVA results for the effects of plant age and Capsicum accession on larval development of Frankliniella occidentalis

\begin{tabular}{|c|c|c|c|c|c|}
\hline $\begin{array}{l}\text { Source of } \\
\text { variation }\end{array}$ & d.f. & $\begin{array}{l}\text { Sum of } \\
\text { squares }\end{array}$ & Mean square & $F$ ratio & $P$ \\
\hline Plant age & 2 & 3.90 & 1.95 & 27.87 & $<0.001$ \\
\hline Accession & 8 & 28.86 & 3.61 & 51.62 & $<0.001$ \\
\hline $\begin{array}{l}\text { Plant age- } \\
\text { accession }\end{array}$ & 16 & 5.40 & 0.34 & 4.83 & $<0.001$ \\
\hline Residual & 183 & 12.79 & 0.07 & & \\
\hline Total & 209 & 50.95 & & & \\
\hline
\end{tabular}

found in six of the nine tested accessions (Table 3). In five of these accessions (PRI1996112, PRI1996236, CGN17042, CGN20503 and CGN16975), a significantly lower average fraction of L1 was found after 7 days when the plants were 4 weeks old, compared to the plants from the same accession that were 8 or 12 weeks old. In one of the accessions, the most susceptible accession CGN17219, a significantly higher average fraction of L1 was found after 7 days in 4-week-old plants compared to 8- and 12-week-old plants. We did not find a significant difference between 8- and 12-week-old plants among all tested accessions.

\section{Leaf age experiment}

To study the possible effect of leaf age on resistance, we selected the most susceptible and the most resistant accession from the plant age experiment, CGN17219 and CGN16975, respectively. The two-way ANOVA showed a significant interaction between accession and leaf age on larval development $(P<0.001$, Table 4$)$. Leaf age affected larval development in the resistant and susceptible accession in opposite ways (Table 5). In the resistant accession, we found that on the youngest fully opened leaf the fraction of L1 larvae was significantly higher than on leaves of the other ages. In the susceptible accession, we found that larval development significantly increases as leaf age decreases.

Furthermore, it was shown that the differences in larval development when comparing leaves of the same age between the susceptible and resistant accession were significant when the leaf was 6 weeks or younger (Table 5). The largest contrast between the accessions was found in the youngest leaves. When leaves were 8 weeks old, no

Table 3 Larval development of Frankliniella occidentalis in nine Capsicum accessions at different plant ages

\begin{tabular}{|c|c|c|c|c|c|}
\hline \multirow[t]{2}{*}{ Accession code } & \multirow[t]{2}{*}{ Accession } & \multirow[t]{2}{*}{ Level of resistance ${ }^{a}$} & \multicolumn{3}{|c|}{ Average Fraction of L1 (7dpi) per plant age ${ }^{b}$} \\
\hline & & & 4 weeks & 8 weeks & 12 weeks \\
\hline CGN17219 & C. chinense no 4661 & $\mathrm{~S}(2.6)$ & $0.06(b c)$ & 0.00 (a) & 0.00 (a) \\
\hline PRI1996108 & C. chinense PI 281428 & $\mathrm{~S}(2.9)$ & $0.11(\mathrm{~cd})$ & 0.17 (cde) & $0.13(\mathrm{~cd})$ \\
\hline PRI1996112 & C. chinense $\mathrm{PI} 315023$ & $\mathrm{~S}(2.8)$ & $0.02(\mathrm{ab})$ & 0.37 (defg) & 0.29 (def) \\
\hline PRI2004001 & C. аппиит Bruinsma Wonder & M (1.8) & 0.43 (cdefgh) & 0.18 (cde) & 0.15 (cde) \\
\hline CGN22817 & C. frutescens Lombok & M (1.4) & $0.24(\mathrm{def})$ & 0.40 (fgh) & 0.30 (efgh) \\
\hline PRI1996236 & C. annuum Laris & $\mathrm{M}(1.1)$ & 0.17 (cde) & $0.45(h)$ & $0.43(\mathrm{gh})$ \\
\hline CGN17042 & C. baccatum no1553 & $\mathrm{R}(0.8)$ & 0.30 (efgh) & 0.77 (i) & 0.88 (ij) \\
\hline CGN20503 & C. апnиuт Bisbas & $\mathrm{R}(0.6)$ & 0.32 (efgh) & 0.88 (ij) & $0.93(\mathrm{j})$ \\
\hline CGN16975 & С аппиит АС1979 & $\mathrm{R}(0.3)$ & $0.47(\mathrm{~h})$ & $1.00(\mathrm{k})$ & $1.00(\mathrm{k})$ \\
\hline
\end{tabular}

At the indicated plant age, the three youngest fully opened leaves of four plants of the same accession were infested with five L1 larvae in a detached leaf assay and 7 days later, the fraction that remained in L1 stage was determined (average fraction of L1)

${ }^{a}$ Based on the results of previous screening by Maharijaya et al. (2011), in which damage scores were given $(0=$ no injury, $3=$ severe injury, $S$ susceptible, $M$ intermediate resistant, $R$ resistant)

${ }^{\mathrm{b}}$ All means followed by the same letter are not significantly different (Fisher's protected LSD test, $P>0.05$ ) 
Table 4 Two-way ANOVA results for the effects of leaf age and Capsicum accession on larval development of Frankliniella occidentalis

\begin{tabular}{lrllll}
\hline $\begin{array}{l}\text { Source of } \\
\text { variation }\end{array}$ & d.f. & $\begin{array}{l}\text { Sum of } \\
\text { squares }\end{array}$ & Mean square & $F$ ratio & $P$ \\
\hline Leaf age & 4 & 0.84 & 0.21 & 4.54 & 0.002 \\
Accession & 1 & 8.49 & 8.49 & 183.12 & $<0.001$ \\
Leaf age- & 4 & 5.56 & 1.39 & 29.99 & $<0.001$ \\
$\quad$ accession & & & & & \\
$\begin{array}{l}\text { Residual } \\
\text { Total }\end{array}$ & 134 & 6.21 & 0.05 & & \\
\hline
\end{tabular}

Table 5 Larval development of Frankliniella occidentalis in a resistant (CGN16975) and a susceptible (CGN17219) pepper accession on leaves of different ages

\begin{tabular}{lll}
\hline Leaf age & \multicolumn{2}{l}{ Average fraction of $\mathrm{L1}^{\mathrm{a}}$} \\
\cline { 2 - 3 } & CGN16975 & CGN17219 \\
\hline 1 & $0.89(\mathrm{a})$ & $0.09(\mathrm{e})$ \\
2 & $0.69(\mathrm{~b})$ & $0.15(\mathrm{e})$ \\
3 & $0.58(\mathrm{bc})$ & $0.31(\mathrm{~d})$ \\
4 & $0.61(\mathrm{~b})$ & $0.46(\mathrm{c})$ \\
5 & $0.57(\mathrm{bc})$ & $0.52(\mathrm{bc})$ \\
\hline
\end{tabular}

The leaves were tested for larval development when the plant was 12 weeks old in a detached leaf assay, by infesting each leaf with five L1 larvae and determining the fraction of larvae that remained in the L1 stage at 7 days after infestation (average fraction of L1). Leaves of ages $1-5$ were about $0,2,4,6$ and 8 weeks old at time of testing, respectively

${ }^{a}$ All means followed by the same letter are not significantly different (Fisher's protected LSD test, $P>0.05$ )

significant differences between the resistant and susceptible accession were found.

\section{Whole plant damage assay}

In addition to the leaf age experiment, the most resistant accession CGN16975 and most susceptible accession CGN17219 were also used in a no-choice whole plant damage assay when plants were 10 weeks old. The damage was determined by evaluating the five most damaged leaves in five plants of these two accessions. Most thrips damage was found on the oldest leaves in both accessions. Thrips damage score was significantly higher for the susceptible accession CGN17219 than for the resistant accession CGN16975 (Fig. 1).

\section{Oviposition assay}

Plants of the resistant accession CGN16975 were used in an oviposition assay to study whether there is a difference in oviposition on young and old leaves. The total number of

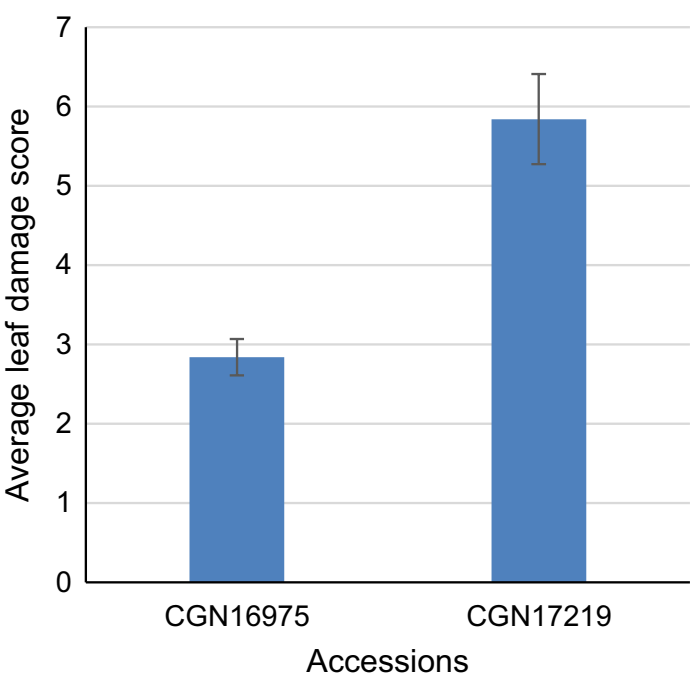

Fig. 1 Average leaf damage score of the five most affected leaves of five whole plants of the resistant accession CGN16975 and the susceptible accession CGN17219. Each plant was infested twice with twenty female adult Frankliniella occidentalis when the plants were 7 and 8 weeks old. The damage of each of the five most affected leaves per plant was scored according to the scale given in Table 1 when the plants were 10 weeks old. The error bars indicate the standard error. The average leaf damage score for CGN16975 was significantly lower than the score for CGN17219 $(P<0.001)$

emerged larvae per $\mathrm{cm}^{2}$ of leaf area at 10 days after infestation was determined. A significantly higher number of larvae per $\mathrm{cm}^{2}$ emerged from young leaves compared to old leaves (Fig. 2).

\section{Discussion}

\section{Plant age affects thrips resistance}

We showed that on 4-week-old plants of all accessions L1 larvae can develop to the L2 stage, although there are significant differences between the accessions. Between plant ages of 4 and 8 weeks, we observed an increased resistance in five of the accessions (Table 3). This transition was most marked on CGN16975, the most resistant accession included in this study, on which about half of the L1 larvae were able to develop into the next stage on 4 weeks old plants; whereas on 8- or 12-week-old plants they did not develop at all beyond the L1 stage. This finding suggests that thrips resistance increases with plant age. Differences in insect resistance between plants of different ages is also found in other crops. For instance, Bemisia tabaci (Gennadius) resistance in Solanum pennellii L. is higher in 20-week-old plants than in 6-week-old plants (Van den Oever-Van den Elsen et al. 2016), and 12-week-old Brassica oleracea L. plants have higher resistance to the whitefly Aleyrodes proletella $\mathrm{L}$. 


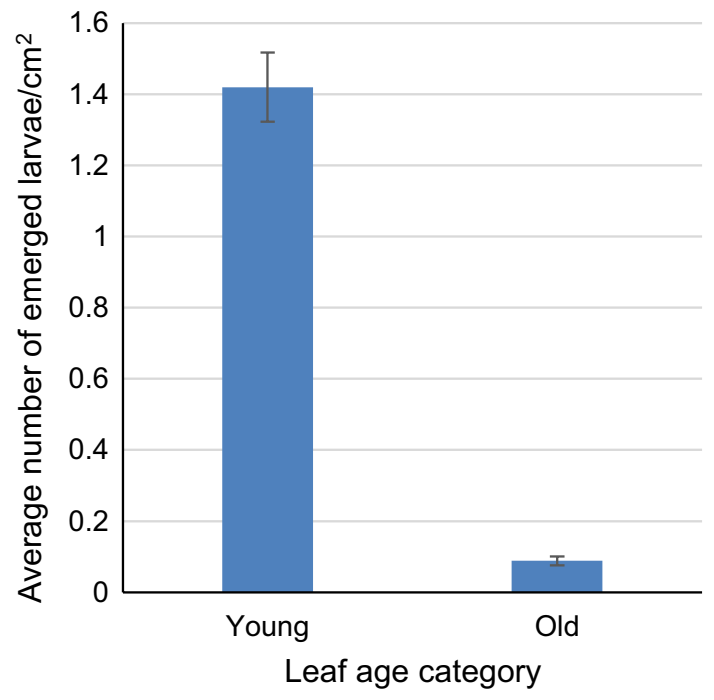

Fig. 2 Average number of emerged larvae per $\mathrm{cm}^{2}$ of leaf area in young and old leaves of three lower side branches of three plants of CGN16975 at $10 \mathrm{dpi}$. Each side branch was infested with 75 female adult Frankliniella occidentalis for 3 days. Up to 10 days after infestation, the emerged larvae on the 40 youngest and 40 oldest leaves of each side branch were counted. The error bars indicate the standard error of the mean. The average number of emerged larvae per $\mathrm{cm}^{2}$ was significantly lower in old leaves compared to young leaves $(P<0.001)$

than 6-week-old plants (Broekgaarden et al. 2012). Whether the resistance that is developing with plant age in the resistant Capsicum accessions is constitutive (also present in the absence of the thrips) or induced by thrips feeding remains an open question. Further research may shed light on this. We also observed a clear interaction between plant age and accession. In contrast to resistant accessions, susceptible accessions do not show a significant increase in thrips resistance when plant age increases.

\section{Leaf age affects thrips resistance}

We observed significant differences in thrips resistance between young and older leaves of the resistant accession CGN16975 and the susceptible accession CGN17219. When comparing the leaves between the two accessions, no significant difference in thrips resistance was found between the oldest leaves of the resistant and susceptible accession; on these leaves, almost half of the L1 larvae develop into the next stages on both accessions. In the resistant accession CGN16975, the youngest fully opened leaves show the highest thrips resistance. A similar observation was made in Senecio, in which Leiss et al. (2009) found a significant positive correlation between leaf age and silvering damage in a choice assay, suggesting a higher thrips resistance in younger leaves. Another example of higher insect resistance in younger leaves is described by Alvarez et al. (2014), who found that green peach aphid Myzus persicae (Sulzer) resistance in younger leaves of potato was higher than in older leaves. In contrast, the susceptible pepper accession CGN17219 shows a higher larval development on younger leaves compared to older leaves. The contrasting effect on larval development on the resistant and susceptible accession can explain the observed interaction between leaf age and accession in their effect on larval development. The higher larval development on younger leaves of the susceptible accession may be explained by higher nutrition and water contents of young compared to old or senescent leaves (Mattson 1980; Boege and Marquis 2005). A similar observation was made by De Kogel et al. (1997), who observed a higher thrips reproduction on apical leaves compared to middle or basal leaves, both in a choice and non-choice study on three partially resistant and one susceptible cucumber accession. These studies used different methods and criteria than we did, so a direct comparison with the outcomes of these studies is not possible. However, these results suggest that in general, young leaves are better suited for thrips performance than older leaves, but that resistance, if present, is expressed most strongly in the younger leaves, resulting in a trade-off. The differences in thrips resistance between young and old leaves in both the resistant and the susceptible accession might be related to the levels of defence compounds. In general, young leaves often contain higher concentrations of defence compounds than older leaves (McCall and Fordyce 2010).

The results from the leaf age experiment agree with our observations in the whole plant damage assay. The average damage score of all leaves evaluated for thrips damage per accession shows that the resistant CGN16975 plants received a significantly lower damage score than the susceptible CGN17219. This difference is found despite the lower level of thrips resistance in the older leaves compared to the youngest leaves within plants of the resistant accession, indicating that the thrips resistance in the youngest leaves does reduce whole plant thrips damage. In this no-choice experimental set-up, the thrips caused silvering damage to the older leaves in the resistant accession as well, which raises the question whether the thrips oviposit on the older leaves, enabling them to reproduce on this accession. In potato, Alvarez et al. (2014) showed that young leaves were resistant to the green peach aphid, but that the insects survive and reproduce on older leaves. The oviposition assay showed that female adult thrips oviposit on both old and young leaves. Despite the resistance against thrips in the young leaves, females laid a significantly higher number of eggs per $\mathrm{cm}^{2}$ on young leaves compared to old leaves, suggesting that the resistance in the young leaves is useful, as newly emerged larvae on young leaves are directly exposed to host plant resistance. Badenes-Perez et al. (2014) described a similar observation in plants of the genus Barbarea: Plutella 
xylostella L. laid more eggs on young leaves compared to older leaves although the abundance of two plant secondary metabolites that were suggested to play a role in plant defence and feeding deterrence was higher in young leaves.

Based on these findings, we formulated the following hypothesis. In general, leaf nutritional quality decreases as leaves grow older (Mattson 1980; Boege and Marquis 2005). Because of the better leaf quality, thrips larvae perform better on young leaves than on old leaves of susceptible accessions. In resistant accessions, the resistance is highly expressed only in young leaves, thus preventing the thrips to develop there. During ageing of the leaves the resistance factor decays, resulting in similar levels of susceptibility in the older leaves of both resistant and susceptible accessions. As female adult thrips strongly prefer to oviposit on young leaves of a resistant plant, this suggests they are unable to detect or react to (a) resistance factor(s) that affect first instar larvae negatively. Therefore, a high resistance level in young leaves is useful for the plant despite the susceptibility of older leaves.

\section{Implications for plant resistance breeding and integrated pest management}

This study provides information to improve the methods to determine host resistance against thrips in Capsicum. The plant age experiment shows that the level of thrips resistance can be determined when plants are 8 weeks old instead of 12 weeks old, because no significant difference in thrips resistance in 8 and 12 weeks old plants was found. The leaf age experiment shows that the largest contrast in thrips resistance between a resistant and a susceptible accession was found in the youngest leaves, indicating that a comparison between these leaves could provide most information on the mechanism of the resistance based, e.g. on gene and protein expression and metabolite profile. The whole plant damage assay shows that, although the older leaves of the resistant accession do not provide resistance against thrips, the resistance in the younger leaves does affect thrips damage, probably because oviposition predominantly takes place on these young leaves as shown by the oviposition assay. Therefore, this study shows that CGN16975 is a potential donor for host plant resistance against thrips.

The outcome of this study also provides information for pest management and crop protection. Considering that female adults can lay four to five eggs per day in an optimal environment in the absence of pollen (Van Rijn et al. 1995), the number of thrips can still increase rapidly and can subsequently cause large damage to the plant as almost half of the L1 can develop into L2 in young resistant plants. Therefore, it is important to protect plants until thrips resistance is fully expressed. It is recommended to use protection measures in combination with host plant resistance to limit the growth and spread of the thrips population. Extra protection can be provided for instance by applying UV-reflective mulch (Reitz et al. 2003) or by using water or sticky traps with attractive volatiles (Teulon et al. 1993; Koschier et al. 2000; Tang et al. 2016), leading to a decrease in number of F. occidentalis adults. Moreover, using a natural predator such as Orius insidiosus in an early plant stage can lead to a much greater decrease in number of $F$. occidentalis, thus keeping the thrips population below the economic threshold (Ramachandran et al. 2001).

Acknowledgements We thank Betty Henken and Mengjing Sun for assistance with carrying out the detached leaf assays. This research was financially supported by a grant (TKI 1409-045) from the Ministry of Economic Affairs of the Netherlands and the breeding companies Nunhems Netherlands B.V. and Bejo Zaden B.V.

Open Access This article is distributed under the terms of the Creative Commons Attribution 4.0 International License (http://creativeco mmons.org/licenses/by/4.0/), which permits unrestricted use, distribution, and reproduction in any medium, provided you give appropriate credit to the original author(s) and the source, provide a link to the Creative Commons license, and indicate if changes were made.

\section{References}

Alvarez AE, Alberti D'Amato AM, Tjallingii WF, Dicke M, Vosman B (2014) Response of Solanum tuberosum to Myzus persicae infestation at different stages of foliage maturity. Insect Sci 21:727-740. https://doi.org/10.1111/1744-7917.12072

Badenes-Perez FR, Gershenzon J, Heckel DG (2014) Insect attraction versus plant defense: young leaves high in glucosinolates stimulate oviposition by a specialist herbivore despite poor larval survival due to high saponin content. PLoS ONE 9:e95766. https ://doi.org/10.1371/journal.pone.0095766

Boege K, Marquis RJ (2005) Facing herbivory as you grow up: the ontogeny of resistance in plants. Trends Ecol Evol 20:441-448. https://doi.org/10.1016/j.tree.2005.05.001

Broekgaarden C, Snoeren TAL, Dicke M, Vosman B (2011) Exploiting natural variation to identify insect-resistance genes. Plant Biotechnol J 9:819-825. https://doi.org/10.1111/j.1467-7652.2011.00635 .X

Broekgaarden C, Riviere P, Steenhuis G, Del sol Cuenca M, Kos M, Vosman B (2012) Phloem-specific resistance in Brassica oleracea against the whitefly Aleyrodes proletella. Entomol Exp Appl 142:153-164. https://doi.org/10.1111/j.1570-7458.2011.01210.x

Chisholm IF, Lewis T (1984) A new look at thrips (Thysanoptera) mouthparts, their action and effects of feeding on plant tissue. Bull Entomol Res 74:663-675. https://doi.org/10.1017/S0007 485300014048

Cloyd RA (2009) Western flower thrips (Frankliniella occidentalis) management on ornamental crops grown in greenhouses: have we reached an impasse. Pest Technol 3:1-9

De Kogel WJ, Balkema-Boomstra A, Van der Hoek M, Zijlstra S, Mollema C (1997) Resistance to western flower thrips in greenhouse cucumber: effect of leaf position and plant age on thrips reproduction. Euphytica 94:63-67. https://doi.org/10.1023/A:10029 37709157

Eigenbrode SD, Espelie KE (1995) Effects of plant epicuticular lipids on insect herbivores. Annu Rev Entomol 40:171-194 
German TL, Ullman DE, Moyer JW (1992) Tospoviruses: diagnosis, molecular biology, phylogeny, and vector relationships. Annu Rev Phytopathol 30:315-348

Glas J, Schimmel B, Alba J, Escobar-Bravo R, Schuurink R, Kant M (2012) Plant glandular trichomes as targets for breeding or engineering of resistance to herbivores. Int J Mol Sci 13:17077. https ://doi.org/10.3390/ijms131217077

Kirk WDJ, Terry LI (2003) The spread of the western flower thrips Frankliniella occidentalis (Pergande). Agric For Entomol 5:301310. https://doi.org/10.1046/j.1461-9563.2003.00192.x

Koschier EH, De Kogel WJ, Visser JH (2000) Assessing the attractiveness of volatile plant compounds to western flower thrips Frankliniella occidentalis. J Chem Ecol 26:2643-2655. https:// doi.org/10.1023/A:1026470122171

Leiss KA, Choi YH, Abdel-Farid IB, Verpoorte R, Klinkhamer PGL (2009) NMR Metabolomics of thrips (Frankliniella occidentalis) resistance in Senecio hybrids. J Chem Ecol 35:219-229. https:// doi.org/10.1007/s10886-008-9586-0

Leite GLD, Picanço M, Guedes RNC, Zanuncio JC (2001) Role of plant age in the resistance of Lycopersicon hirsutum f. glabratum to the tomato leafminer Tuta absoluta (Lepidoptera: Gelechiidae). Sci Hortic 89:103-113. https://doi.org/10.1016/S0304 -4238(00)00224-7

Linders EGA, Nicolet JLME, Van Wijk HJ (2010) Insect resistant plant. US Patent 8,993,855 B2

Lublinkhof J, Foster DE (1977) Development and reproductive capacity of Frankliniella occidentalis (Thysanoptera: Thripidae) reared at three temperatures. J Kansas Entomol Soc 50:313-316

Maharijaya A, Vosman B, Steenhuis-Broers G, Harpenas A, Purwito A, Visser RGF, Voorrips RE (2011) Screening of pepper accessions for resistance against two thrips species (Frankliniella occidentalis and Thrips parvispinus). Euphytica 177:401-410. https://doi. org/10.1007/s10681-010-0277-x

Maharijaya A, Vosman B, Verstappen F, Steenhuis-Broers G, Mumm R, Purwito A, Visser RG, Voorrips RE (2012) Resistance factors in pepper inhibit larval development of thrips (Frankliniella occidentalis). Entomol Exp Appl 145:62-71. https://doi.org/10.1 111/j.1570-7458.2012.01304.x

Mattson WJ (1980) Herbivory in relation to plant nitrogen content. Annu Rev Ecol Syst 11:119-161. https://doi.org/10.1146/annur ev.es.11.110180.001003

McCall AC, Fordyce JA (2010) Can optimal defence theory be used to predict the distribution of plant chemical defences? J Ecol 98:985-992. https://doi.org/10.1111/j.1365-2745.2010.01693.x

McDonald JR, Bale JS, Walters KFA (1998) Effect of temperature on development of the western flower thrips, Frankliniella occidentalis (Thysanoptera: Thripidae). EJE 95:301-306

Mirnezhad M, Romero-González RR, Leiss KA, Choi YH, Verpoorte R, Klinkhamer PGL (2010) Metabolomic analysis of host plant resistance to thrips in wild and cultivated tomatoes. Phytochem Anal 21:110-117. https://doi.org/10.1002/pca.1182

Mollema C, Steenhuis M, Inggamer H, Soria C (1993) Evaluating the resistance to Frankliniella occidentalis in cucumber: methods, genotypic variation and effects upon thrips biology. IOBC/WPRS Bull 16:77-82

Mouden S, Sarmiento KF, Klinkhamer PG, Leiss KA (2017) Integrated pest management in western flower thrips: past, present and future. Pest Manage Sci. https://doi.org/10.1002/ps.4531
Ramachandran S, Funderburk J, Stavisky J, Olson S (2001) Population abundance and movement of Frankliniella species and Orius insidiosus in field pepper. Agric For Entomol 3:129-137. https:// doi.org/10.1046/j.1461-9563.2001.00097.x

Reitz SR, Yearby EL, Funderburk JE, Stavisky J, Momol MT, Olson SM (2003) Integrated management tactics for Frankliniella thrips (Thysanoptera: Thripidae) in field-grown pepper. J Econ Entomol 96:1201-1214. https://doi.org/10.1603/0022-0493-96.4.1201

Schneider CA, Rasband WS, Eliceiri KW (2012) NIH Image to ImageJ: 25 years of image analysis. Nat Methods 9:671 https:// doi.org/10.1038/nmeth.2089

Shipp JL, Hao X, Papadopoulos AP, Binns MR (1998) Impact of western flower thrips (Thysanoptera: Thripidae) on growth, photosynthesis and productivity of greenhouse sweet pepper. Sci Hortic 72:87-102. https://doi.org/10.1016/S0304-4238(97)00130-1

Siemonsma J, Kasem P (1994) Vegetables; plant resources of the South east Asia (PROSEA). J Ethanopharmacol 46:130-156

Smith CM (2005) Plant resistance to arthropods: molecular and conventional approaches. Springer, Dordrecht

Tang LD, Zhao HY, Fu BL, Han Y, Liu K, Wu JH (2016) Colored sticky traps to selectively survey thrips in cowpea ecosystem. Neotrop Entomol 45:96-101. https://doi.org/10.1007/s1374 4-015-0334-1

Teulon DAJ, Penman DR, Ramakers PMJ (1993) Volatile chemicals for thrips (Thysanoptera: Thripidae) host finding and applications for thrips pest management. J Econ Entomol 86:1405-1415. https ://doi.org/10.1093/jee/86.5.1405

Tommasini M, Maini S (1995) Frankliniella occidentalis and other thrips harmful to vegetable and ornamental crops in Europe. Wageningen Agricultural University Papers, Wageningen

Van Rijn PC, Mollema C, Steenhuis-Broers GM (1995) Comparative life history studies of Frankliniella occidentalis and Thrips tabaci (Thysanoptera: Thripidae) on cucumber. Bull Entomol Res 85:285-297. https://doi.org/10.1017/S0007485300034386

Van den Oever-Van den Elsen F, Lucatti AF, Van Heusden S, Broekgaarden C, Mumm R, Dicke M, Vosman B (2016) Quantitative resistance against Bemisia tabaci in Solanum pennellii: genetics and metabolomics. J Integr Plant Biol 58:397-412. https://doi. org/10.1111/jipb. 12449

Voorrips RE, Steenhuis-Broers G, Tiemens-Hulscher M, Lammerts van Bueren ET (2008) Plant traits associated with resistance to Thrips tabaci in cabbage (Brassica oleracea var capitata). Euphytica 163:409. https://doi.org/10.1007/s10681-008-9704-7

VSN International (2015) Genstat for Windows, 18th edn. VSN International, Hemel Hempstead

Welter SC, Rosenheim JA, Johnson MW, Mau RFL, Gusukuma-Minuto LR (1990) Effects of Thrips palmi and western flower thrips (Thysanoptera: Thripidae) on the yield, growth, and carbon allocation pattern in cucumbers. J Econ Entomol 83:2092-2101. https://doi. org/10.1093/jee/83.5.2092

Zhang ZJ, Wu QJ, Li XF, Zhang YJ, Xu BY, Zhu GR (2007) Life history of western flower thrips, Frankliniella occidentalis (Thysan., Thripae), on five different vegetable leaves. J Appl Entomol 131:347-354. https://doi.org/10.1111/j.1439-0418.2007.01186.x

Znidarcic D, Valic N, Trdan S (2008) Epicuticular wax content in the leaves of cabbage (Brassica oleracea $\mathrm{L}$. var. capitata) as a mechanical barrier against three insect pests. Acta Agric Slov 91:361. https://doi.org/10.2478/v10014-008-0016-3 